\title{
LA TRANSCOMPLEJIDAD DE LAS \\ TECNOLOGÍAS DE INFORMACIÓN Y \\ COMUNICACIÓN EN LA UNIVERSIDAD \\ DESDE UNA VISIÓN TRIDIMENSIONAL
}

\section{Ramón Gámez}

Universidad Bicentenaria de Aragua, mesineo@live.com

\section{Magaly Ojeda}

Universidad Bicentenaria de Aragua, magalyvict@hotmail.com

\section{Adaisis Valdez}

Universidad Bicentenaria de Aragua, Yosella.valdez@uba.edu.ve

\section{Resumen}

Las universidades, en el cumplimiento de su función han de proveer la formación de profesionales capaces de responder a los requerimientos de la sociedad globalizada. Lo planteado refleja la importancia de una apropiación más proactiva de las tecnologías de información y comunicación y la consecuente incorporación de cambios estructurales en el espacio educativo. Se realizó con base al enfoque integrador transcomplejo y métodos mixtos, en un procedimiento de tres fases: a) documental hermenéutica, donde se discutieron las teorías de sistemas, teoría de la creatividad e innovación, teoría de procesamiento de la información; b) de campo deductiva colaborativa, en la cual el escenario de investigación fue la universidad Bicentenaria de Aragua, con una población siete estudiantes a los cuales se les realizó una entrevista a profundidad y una muestra 905 estudiantes, que representa al 6\% de la población estudiantil, que asciende a 15 mil estudiantes a quienes se les aplicó un cuestionario y c) la integrativa donde se realizó el análisis cuantitativo, la interpretación cualitativa y la integración de los resultados. Se pudo constatar que la apropiación de las tecnologías de información y comunicación en la universidad es medianamente favorable en la dimensión tecnológica. Con base a lo cual se generó un estadio emergente transcomplejo donde se reticulan el espacio virtual, los docentes, los estudiantes y los recursos tecnológicos, con miras a generar innovación y crear una cultura tecnológica en la universidad. 
Palabras clave: universidades, TIC, educación virtual, transcomplejidad.

\section{THE TRANSCOMPLEXITY OF TECHNOLOGIES OF INFORMATION AND COMMUNICATION IN THE UNIVERSITY FROM A THREE-DIMENSIONAL VISION}

\section{Abstract}

Universities, in the fulfillment of their function, must provide the training of professionals capable of responding to the requirements of a globalized society. The proposal reflects the importance of a more proactive appropriation of Information and Communication Technologies and the consequent incorporation of structural changes in the educational space. It was made based on the transcomplex integrative approach and mixed methods, in a three-phase procedure: a) hermeneutical documentary, where the theories of systems, theory of creativity and innovation, theory of information processing; b) collaborative deductive field, in which the research scenario was the Bicentennial University of Aragua, with a population of seven students who were interviewed in depth and a sample of 905 students, representing $6 \%$ of the population student, which amounts to 15 thousand students to whom a questionnaire was applied; and c) the integrative one where the quantitative analysis was carried out, the qualitative interpretation and the integration of the results. It was found that the appropriation of Information and Communication Technologies in the university is fairly favorable in the technological dimension. Based on this, an emerging transcomplex stadium was created, where the virtual space, teachers, students and technological resources are reticulated, with the aim of generating innovation and creating a technological culture in the university.

Keywords: universities, ICT, virtual education, transcomplexity.

Proyecto de investigación base: Visión Transcompleja de las TIC en la Universidad 


\section{Introducción}

Hoy en día, las posibilidades de conexión que ofrece el internet y por consiguiente el intercambio de información entre personas geográficamente distantes, ofrece nuevas oportunidades para ampliar las opciones de aprendizaje. Es un milagro tecnológico que visto de la manera correcta y enfocado adecuadamente contribuirá a la disminución de la brecha digital que los adelantos técnicos y las situaciones internas de los países desarrollados y los que están en vías de desarrollo deben afrontar. La actual disposición de equipos de tecnología a nivel global, las creaciones constantes de nuevas plataformas diseñadas para la formación permiten considerar que su avance en la educación como en los diversos procesos de gestión universitaria es imparable, por lo que la acción siguiente ha de ser, el aprovechar de manera proactiva el abanico de tecnologías existentes en pro de mejorar, afianzar y ampliar las opciones educativas de las personas. En la actualidad se produce una cantidad de información al día nunca antes conocida. Si repasamos toda la capacidad industrial adquirida para lanzar datos y datos al mundo y la comparamos con unas décadas o siglos atrás, no es difícil creerse que lo que antes hemos tardado cientos de años en generar, ahora florezca en pocas horas.

Todo lo anterior, revela la importancia de entender que la era digital influye y es parte de todo el hacer humano, propiciando la rápida divulgación de la información y nuevos conocimientos, generando una espiral indeterminable e infinita capaz de potenciar el crecimiento y desarrollo a niveles impensados, siendo la educación, en todos sus niveles y modalidades, el factor catalizador de este proceso. Desde esta perspectiva, la universidad, como institución dedicada al mundo de la cultura y socialización, no puede quedar ajena a esta dinámica la comunicación, el acceso y manejo del conocimiento que los nuevos tiempos plantean en lo que respecta a las tecnologías de la comunicación e información y su aplicabilidad a la organización educativa, cuya introducción ha permitido una transformación en el sistema universitario, dando lugar a un nuevas visiones que incluyen la diversidad de saberes, el aprendizaje autónomo, autogestionado y colaborativo. En tal sentido, el trabajo aborda el grado de integración de las TIC en la universidad desde 
una visión transcompleja que permitió integrar el ámbito educativo que incluye a los docentes, estudiantes, modelo educativo-, las tecnologías referidas a las plataformas informáticas destinadas al aprendizaje virtual y el marco legal que apoya estas acciones.

\section{La educación en la sociedad del conocimiento}

La incorporación de las TIC, en el ámbito de la educación es ya una realidad, nadie puede pensar en que estos medios de divulgación y facilitación del acceso a la información puedan estar fuera de la ecuación del hecho educativo. Hoy todos los gobiernos del mundo, hasta los más totalitarios, reconocen la necesidad de incorporar el uso de estos medios y de apoyarse en la web como el espacio virtual donde la información fluye libremente y contribuye segundo a segundo a la construcción de conocimientos. Sin embargo, este cambio de paradigma no ha sido un proceso fácil. A principios de la segunda mitad del siglo XX, los variados intentos institucionales que surgieron para generar un posicionamiento de la educación a distancia en el contexto Latinoamericano, chocaron contra el muro de los gobiernos de la región. Salvo excepciones, por lo general los gobiernos se mostraron, o bien contrarios a la legitimación de la modalidad, o bien dudosos y/o dilatorios para producir acciones que enmarcaran, aprobaran, orientaran, promovieran, regularan y evaluaran programas a distancia.

Vale destacar que no fue sino hasta la aparición de la web en la década de los ańos noventa, junto a las tecnologías asociadas que se fueron desarrollando, que los gobiernos latinoamericanos fueron cediendo al cambio y apropiándose de la versatilidad que otorga el manejo inmediato de la información y la facilidad para divulgarla. Según datos de la CEPAL (2000), para finales de la década de los noventa, apenas el $1 \%$ de la población latinoamericana estaba conectada a internet, sin embargo, en muy poco tiempo esto cambio, convirtiéndose Latinoamérica en la primera década del siglo XXI, en el continente con mayor crecimiento en el mundo en uso de internet, en términos porcentuales. Estas tecnologías en las instituciones educativas, no sólo incrementan la productividad intelectual sino que plantean un cambio cualitativo en la naturaleza del aprendizaje, al producir diferentes modos de pensamiento 
que enriquecen la teoría cognoscitiva, brindando la oportunidad de mayor énfasis en habilidades creativas, incremento de la curiosidad, capacidad de respuesta y de evocación, entre otras. Lo anterior refleja la importancia de una apropiación más proactiva de las TIC en la universidad en todos sus niveles, lo que supone la necesidad de desarrollar las competencias tecnológicas que son y serán demandadas por su contexto cotidiano, académico y profesional.

Todo este cambio, evolución, crecimiento y aceptación que ha presentado la modalidad, obliga a una regulación legal, procurando que esta facilite su desarrollo y la creatividad transformadora con un enfoque liberal deslastrado de paradigmas basados en el modelo tradicional. Además, con la generalidad y flexibilidad suficiente que evite su obsolescencia ante la persistente evolución de la TIC y su influencia en la educación. La regulación debe concebirse para facilitar su desarrollo y con la certeza que la influencia de los avances tecnológicos seguirá influyendo en la transformación del hecho educativo. Sin embargo, en criterio de Tedesco (2005), estas promesas de las TIC en la educación están lejos de ser realidad. No se trata de negar la potencialidad democratizadora e innovadora de las nuevas tecnologías, sino enfatizar que el ejercicio de esta no depende de las tecnologías mismas sino de los modelos sociales y pedagógicos en los cuales se utilice. Así es evidente el contraste entre una sociedad altamente comunicada e interconectada y algunas instituciones universitarias que llegan incluso a negar el uso de las tecnologías en sus procesos académicos y administrativos, lo que genera una brecha que no puede negarse.

Evidencia de esto, se tiene en los resultados del informe presentado por la Comisión de Rectores de las Universidades Europeas (CRUE, 2013), donde se señala que: (a) hay poca madurez de la gobernanza de las tecnologías de información; (b) no se cuenta con el equipamiento básico en las aulas, esto es, conexión a internet sea un punto cableado o por WI-FI, así como del proyector para el manejo de las actividades. (c) existe la intención en dichas universidades de apoyo al estudiante al ofrecer espacios de acceso libre a internet, préstamo de equipos de computación portátil o aulas móviles, pero no se materializa en su totalidad. En el ámbito de la gestión de las tecnologías de información, se destaca la disposición de recursos humanos suficientes y bien distribuidos, aunque, el in- 
forme (CRUE, 2013), señala que dos de cada tres universidades carecen de un plan de dotación y distribución de recursos humanos relacionados con las tecnologías de información. Asimismo, se tiene que, el personal suele encontrarse en un $81 \%$ de los casos en servicios centrales sin planes de formación anuales, a pesar de tener en dichas universidades, un presupuesto propio. En lo referente a una planificación ordenada de proyectos de tecnologías de información, no existe o es muy tímido su desarrollo.

En Latinoamérica, la aplicación del estudio señalado anteriormente al 3\% de las universidades existentes, con sus mismos indicadores refleja que existen esfuerzos orientados a la implantación de nuevas tecnologías como apoyo a la docencia presencial, encontrando un porcentaje de aulas con equipamiento básico de tecnologías de información, de 39,23\% mas no se abarca la compleja disposición de tecnologías hacia una educación en línea. Asimismo, el número medio de computadoras portátiles en préstamo a libre disposición de los estudiantes existentes en Latinoamérica es de $51,22 \%$, por universidad, valor que se incrementa para las universidades pertenecientes al Sistema Universitario Español, alcanzando una media de 73,93\%. No refiriéndose al caso Venezuela, donde este porcentaje es considerablemente menor.

También, se debe focalizar la atención al lenguaje tecnológico de los sujetos interactuantes, por un lado, están los jóvenes en su gran mayoría nativos digitales, entendiendo por estos aquellos que son habitantes nativos del lenguaje digital, televisión, videojuegos, computadoras que se distinguen de los inmigrantes digitales, que hablan un idioma en vías de extinción de la era pre digital y están tratando de comunicarse a una población que habla un lenguaje completamente distinto e incomprensible. Esta diferencia fundamental que distingue a las partes en cuestión, pone en evidencia una brecha generacional que debe ser abarcada para poder lograr la anhelada convivencia, entendiendo que los nativos digitales hablan un idioma diferente y ello genera una distancia que el inmigrante, por más esfuerzo que realice, nunca alcanzará equiparar, lo cual representa uno de los factores que contextualizan la realidad de estudio desde la visión del proceso educativo.

En Venezuela, las cifras de la Cámara de Comercio Electrónico (CAVECOM-E, 2006), señalan que el crecimiento del uso de inter- 
net a finales del 2006, estaba en el orden $22 \%$ y su penetración en la sociedad venezolana del 12\%, siendo el promedio en América Latina de $14 \%$. Esto indica que el joven que hoy ingresa a las Universidades nació, creció y se formó en un mundo cada vez más digitalizado, tecnificado y virtual, por tanto sus expectativas de cómo afrontar el proceso educativo y adquirir el conocimiento son totalmente distintas a cómo la conciben los docentes. Tal circunstancia constituye un reto para la educación y se refuerza en los expresado por Sáez (2011), quien afirma que "es obligación como educadores posibilitar el desarrollo en los estudiantes de competencias para el manejo, uso y aprovechamiento de las herramientas tecnológicas" (p.35).

No obstante, el modelo educativo en Venezuela, en todos sus niveles y modalidades, fue concebido para brindar respuestas a una realidad de mediados del siglo pasado y ejecutar el proceso pedagógico en el contexto de aquella realidad. Lo que significa, que igual que en Europa los docentes no están lo suficientemente preparados para utilizar todas las potencialidades de las TIC. En cuanto a la normativa legal de la educación a distancia con soporte tecnológico se han hecho algunos avances, pero no se ha logrado consolidar una normativa propia. Por su parte, la nueva Ley Orgánica de Educación, en lo que puede considerarse, a juicio de Gámez (2016), un error de técnica legislativa, definió las modalidades del sistema educativo subestimando la dinámica cambiante de los hechos sociales que se regulan con esta Ley.

En este sentido, la Ley Orgánica de Educación (2009), debió dejar abiertos los espacios para adaptarse a los cambios que se vienen desarrollando en procura de la democratización de la información, la construcción del conocimiento colectivo y la incorporación de las TIC dentro del contexto nacional, la sociedad, la cultura y por sobre todo permeando en el sistema educativo, como garantía del desarrollo de la nación. A nivel educativo, se percibe desvinculación entre la formación que posee el docente, la falta de instrucción al estudiante en el manejo TIC en EaD y los notables avances tecnológico lo que genera una serie de inconsistencias en el modelo de educación universitario, tales como: desfase respecto al contenido, aprendizaje incompleto y superficial con poca profundidad en los diferentes temas y el manejo no adecuado del aula virtual, lo que implica no conocer sus aplicaciones educativas. Esta dicotomía 
se manifiesta en el papel del docente mediador de las TIC, amerita una transformación en los esquemas de pensamiento y actitud hacia la enseńanza, la preparación en manejo de TIC con la correcta valoración de su condición de experticia en el tema que le corresponde desarrollar.

En cuanto a los estudiantes, nativos digitales en su mayoría, consustanciados con el entorno tecnológico en todos los espacios de su vida, presentan debilidades a la hora de canalizar el uso de esa tecnología que reina a su alrededor en actividades puntuales de estudio e investigación, debido a que no se aprovecha el potencial de las TIC, sobre todo en la interacción en las redes sociales llegando a observarse la existencia de condicionamientos del uso de los equipos propios como laptop, tabletas y teléfonos inteligentes en las aulas de clase. Lo que refleja dos condiciones que es imperativo afrontar: en primer lugar, los estudiantes aun cuando las poseen no utilizan las TIC de forma apropiada en su proceso de aprendizaje y, un segundo aspecto, las instituciones al visualizarlos como nativos digitales no prevén asignaturas iniciales para valorar competencias y habilidades con respecto al adecuado uso de las TIC. Ambas consideraciones deben ser atendidas desde la premisa de una enseńanza para aprender, desaprender y reaprender; desde la perspectiva andragógica de construir redes de conocimiento; de posibilitar la extracción de lo importante en medio de todo ese mar de conocimiento, de concientizar sobre el potencial de las TIC para una formación de excelencia.

Entendiendo que esta realidad densa ha de abarcarse desde distintas dimensiones del conocimiento que articulan las consideraciones jurídicas, el desarrollo de la cadena pedagógica, la informática, ciencias de la comunicación, la psicología, la economía, la ingeniera, entre otras disciplinas, es decir, desde una mirada transdisciplinaria, considerando la complejidad de los elementos y acciones intervinientes en el proceso educativo y el desarrollo de la tecnología per se, la investigación explora la apropiación de las TIC en la Universidad considerando las transcomplejidades emergentes en la ecología de las acciones legales, tecnológicas y educativas. La sociedad de la información, es un movimiento que surge de la mano de la revolución del conocimiento, donde se desarrollan transformaciones de índole políticas, sociales y económicas apuntaladas por una conse- 
cuente ampliación de la tecnología y su uso en el procesamiento y manejo de la información. La producción y generación de conocimiento conduce a entornos más igualitarios de libertad y permite dinamizar la sociedad a través del mismo, cuando se concibe como principio fundamental la disponibilidad de la información a todos y en todas partes. De este modo, se reconoce la viabilidad de un incremento en el nivel de educación y en el desarrollo socioeconómico de las personas a partir de este bien inmaterial que llega con la tecnología, reafirmando su valor como un bien social, imprescindible para el desarrollo al contribuir a la obtención, consolidación y generación del conocimiento científico.

El aprovechamiento que en términos de desarrollo social, traen consigo las comunicaciones se manifiesta en la construcción de un nuevo contexto, que mejora las relaciones humanas al conformarse una sociedad informada y bien comunicada. $\mathrm{Al}$ respecto, Carneiro (2009), expresa que la literatura acerca de las TIC tiende a presentarlas como un gran factor igualador de oportunidades que incluye aprender independientemente de la localización física de los sujetos; acceder a un aprendizaje interactivo y a propuestas de aprendizaje flexibles que permitan superar la situación de acceso limitado a la información que tienen principalmente los países pobres. En este sentido, el acceso a Internet no se considera solo un problema de acceso a las herramientas. La tenencia de computador en el hogar no se traduce en tenencia de internet, pues también implica las capacidades, habilidades y necesidad del hogar de utilizarla. Así, la educación se convierte en una variable fundamental para la consolidación de la sociedad de la Información en la medida que los países avancen en la instalación de infraestructuras y en la disminución de los costos de acceso de las TIC.

De la misma forma, debe invertir mucha energía en la comprensión de las ganancias potenciales que el uso de estas herramientas pueden significar y los beneficios puede traer al desarrollo económico, el bienestar social y la participación del ciudadano en el contexto de la sociedad de la información. Es de mucha importancia, por tanto, entender las posibilidades que las TIC ofrecen y cuáles son las limitaciones que los diversos grupos de la sociedad pueden tener en apropiarse de las mismas para potenciar el uso de las TIC de acuerdo con sus características, intereses y limitaciones. 
Desde esta perspectiva, se desprende el Índice de la sociedad de la información (ISI), como instrumento que permite medir el avance y acceso a la información, capacidad de adoptar tecnologías de información y habilidad para su incorporación de forma útil y apropiada según el Programa de las Naciones Unidas para el Desarrollo (2011), adaptado a la realidad de la universidad. La institución universitaria como agente de cambio y transformación de la sociedad, merece ser analizada e incluida en los indicadores orientados a la medición del índice de la sociedad de la información. Más aún, siendo ésta un sistema complejo de articulación interna y externa debe contar con la estructura de medición de sí misma.

A tales efectos, los investigadores definen lo que debe ser el Índice de la Sociedad de la Información Universitario (ISIU), que no es más que la extrapolación del esquema de medición de un sistema mayor como lo es la sociedad a un sistema menor representado por las universidades. El ISIU, pretende dar testimonio de la preparación de la universidad para apropiarse de las TIC en su seno, basado en el rendimiento que pueden tener los resultados en el desarrollo humano debido a las TIC como equipo o servicio que proporciona una funcionalidad completa de adquisición, almacenamiento, procesado, presentación y comunicación de la información. Partiendo de estudios de aptitud digital, desarrollados por la UNESCO (2013), se conceptualiza desde la disposición de uso y acceso a las tecnologías de forma de lograr la comunicación de la información. Asimismo, es importante valorar la intensidad de la integración de las TIC, reflejado en el desarrollo y uso de los contenidos digitales, preparados y organizados por la Institución, propendiendo al fin de equidad social y competitividad. Así pues, se presenta el cuadro Nro. 1, donde se visualizan los ámbitos de infraestructura en sus ramas disposición y acceso, la e-intensidad reflejada en el desarrollo de la Infoestructura y el uso de la misma. Para finalmente analizar el impacto. 
Cuadro 1 Relación de datos necesarios para calcular el ISIU

\begin{tabular}{|l|l|}
\hline Aptitud Digital - Disposición & E-intensidad - Desarrollo \\
\hline Nro. PC per Cápita & Nro. actividades y procesos \\
Nro. PC disponible en los laboratorios & administrados ví web \\
Nro. PC disponible en la biblioteca & Nro. programas formativos \\
Nro. estudiantes con PC en su hogar & disponibles en la web \\
Nro. Servidores activos & Nro. Página Web Institucionales \\
Nro. Redes internas & Nro. cuentas Facebook Institucionales \\
Capacidad de ancho de banda & Nro. cuentas twitter institucionales \\
contratada & \\
Nro. líneas telefónicas en la Institución & \\
Nro. equipos de video disponibles a la & \\
PU & \\
Nro. estudiantes con computador & \\
portátil & \\
Nro. estudiantes con teléfono & \\
residencial & \\
Nro. estudiantes con tlf móvil & \\
Nro. estudiantes con tlf inteligente & \\
Nro. estudiantes con tabletas o ipads & \\
\hline Aptitud Digital - Acceso & \\
\hline Nro. Usuarios con acceso a servicios & Nro. usuarios activos en el aula virtual \\
\hline web & \\
Nro. usuarios que disponen de cuenta & Nro. lectores página web \\
en Facebook & Nro. seguidores cuentas Facebook \\
Nro. usuarios que disponen de cuenta & Nro. seguidores cuentas twitter. \\
en twitter & \\
Nro. usuarios con blog & \\
Nro. usuarios del Aula virtual & \\
Nro. usuario con internet en casa & \\
Nro. usuarios con acceso a internet & \\
\hline E Impacto & \\
\hline Normativa de Telecomunicaciones \\
Normas internas de acceso y uso de servicios \\
Nro. usuarios de equipos en labs \\
Nro. usuarios de biblioteca digital \\
Nro. usuarios de equipos móviles para actividades educativas \\
Nro. usuarios equipos de tecnología \\
Nro. usuarios equipos para investigación \\
\hline
\end{tabular}

Fuente: Elaboración propia (2016)

Las TIC, favorecen una posibilidad nunca antes vista de intercambio de datos en todos los niveles y aspectos de la sociedad, sus 
beneficios son tangibles, de un valor incalculable del cual no puede ser privado ninguna persona, en especial del espacio venezolano. Este principio se expone en la Constitución de la República Bolivariana de Venezuela (1999), reconociendo de esta manera tanto la importancia del ciudadano como de la información a que este puede acceder y disfrutar para beneficio propio y del colectivo. La Educación Universitaria, como proceso formativo y soporte fundamental de la construcción social, necesita valerse de todas las herramientas que estén a su disposición y dado el rol que juega en la formación de los ciudadanos y ciudadanas, no puede quedarse relegada del avance tecnológico. Por lo que la presencia de las TIC es indispensable en tanto y cuanto se logre que los desarrollos tecnológicos sean accesibles para todos y todas, ya sea por su fácil manejo, como por sus costos bajos y enmarcados dentro de los presupuestos de las universidades y sobre todo acordes con la realidad de cada uno de los países. Esto último, reconoce la necesidad de abrirse al diálogo entre las diversas formas de conocimiento, con actitud positiva y proactiva, proclive a la participación en la construcción de mejores espacios para la formación y difusión del conocimiento.

Los distintos elementos que configuran la inclusión de la TIC en los entornos universitarios a juicio de la investigadora Valdez (2016), comprenden:

- Infraestructura tecnológica, como los elementos físicos y primer nivel de análisis;

- Capa de estructura virtual, donde se incluyen las políticas de uso y acceso a la internet y el software asociado a procesos administrativos y académicos, incluyendo dentro de éstos los dedicados a procesos de enseñanza denominados Learning Management System (LMS);

- Elementos educativos que conforman el ambiente web, donde se ubica la didáctica y estrategias de facilitación del aprendizaje, entrelazadas con los perfiles y el currículo.

- Aspectos normativos, que incluyen las leyes, reglamentos y demás consideraciones legales que inciden en el uso de la tecnología de la Información y comunicación en los entornos universitarios, tal como se muestra en la figura 1, a continuación. 
Figura 1.

Elementos del modelo interacción TIC en la universidad

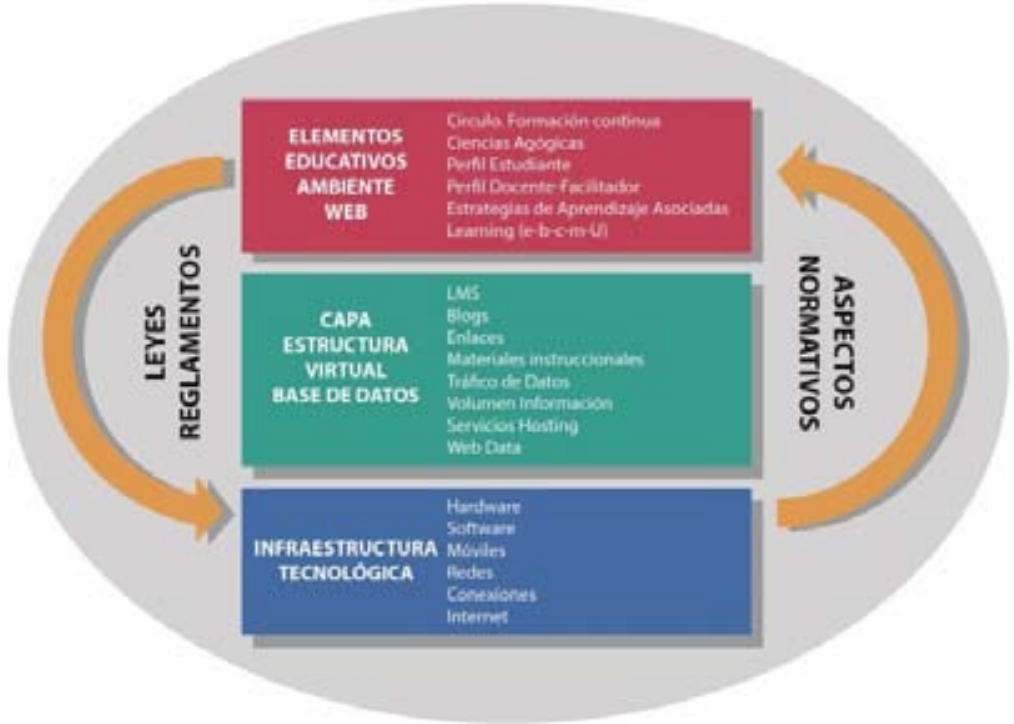

Fuente: Elaborado por Valdez (2016)

De acuerdo a Orozco (2014), el uso apropiado y estratégico de las TIC en estos espacios ayuda a mejorar el proceso de aprendizaje de los estudiantes, y dinamizan, mas no reemplazan, las actividades que el docente propone en el aula, de quien depende en alto grado el éxito de su aplicación. Por su parte, Carrillo (2010), señala la importancia de la aplicación de esfuerzos en las tecnologías en un cambio cultural organizativo centrado en la prestación de servicio al usuario y en la capacitación y valoración del capital humano, más allá de incorporación de la tecnología por sí misma. Aquí se enfoca la teoría de la innovación y cambio tecnológico, como promotora del proceso interactivo que se da en la organización en un aprendizaje constante que se transforma en un sistema complejo de aprender-desaprender considerando las relaciones internas y externas al coexistir con su entorno. En este sentido, Valdez (2014), señala que "las universidades, además de su función primordial de formación de profesionales capaces de responder a los requerimientos del sector productivo, de la sociedad y del país; deben dar respuesta como organizaciones de servicios basados en criterios de calidad y 
tiempo, orientados a la satisfacción de necesidades de información" (p.4). Aquí se destacan la existencia de procesos administrativos necesarios para el funcionamiento de las instituciones de Educación Superior, que deben ser correctamente gestionados para prestar un servicio de calidad a los clientes y asegurar su fortalecimiento y permanencia en el tiempo, consagrando la excelencia como el norte de cualquier acción emprendedora.

\section{Modelos de aprendizaje virtual}

Lo modelos son representaciones, de un proceso con un fin determinado. En este caso el patrón de aprendizaje se refiere a los procesos mediante los cuales el alumno aprende. Estas maneras de abordar el aprendizaje por parte del estudiante, considerando estrategias y enfoques como constructos descriptivo-explicativos, dependen de diversas razones, que determinan el uso de una particular. Un modelo pedagógico establece lineamientos necesarios para desarrollar los ambientes de aprendizaje en un aula presencial o no presencial. Los mismos son proyectados para crear las condiciones pedagógicas y contextuales, donde su objetivo es lograr el conocimiento. La educación a distancia empleando herramientas telemáticas permite desarrollar un proceso centrado en el estudiante donde se respete los diferentes estilos de aprendizaje para lo cual se debe tener presente un modelo pedagógico adecuado.

Es evidente que existen cambios importantes y transformaciones en los procesos educativos producto de la evolución tecnológica y la dinámica económica y política de esta era. El conocimiento es clave en el desarrollo de la humanidad, considerando las diferentes teorías tradicionalmente utilizadas en los entornos educativos y desarrollados en tiempos donde no existían los avances tecnológicos de hoy. Así, como las que se presentan en la actualidad producto de la globalización. El nuevo paradigma educativo se basa en el cambio del perfil del profesor, el cambio del rol de los estudiantes, la eliminación de las barreras espacio temporales, y la integración curricular de los contenidos en cada una de las distintas áreas temáticas. De ahí la importancia de formación de todos los actores del contexto educativo en el manejo de la TIC. De igual forma, los entornos virtuales exigen una transformación en la rutina pedagó- 
gica y didáctica, logrando modificaciones desde los docentes con los planes de trabajo y propósitos de las evaluaciones hasta los estudiantes con motivación, conocimientos y habilidades adaptadas a las tecnologías. Esto da paso a diversidad de opciones en las que las TIC han podido ser incorporadas en el proceso educativo, y que por consiguiente han modificado las actuaciones de los actores del proceso dando lugar a nuevos modelos educativos. En el cuadro 2, a continuación, se evidencia el estado del arte de esta relación.

\section{Cuadro 2.}

Estado del arte. Relación aprendizaje-tecnología

\begin{tabular}{|l|l|}
\hline Estadio & Relación con el Aprendizaje y la TIC \\
\hline ULEARNING & $\begin{array}{l}\text { Es el conjunto de actividades formativas, apoyadas en la } \\
\text { tecnología, y que están realmente accesibles en cualquier } \\
\text { lugar. Es en realidad, la versión tecnológica del aprendizaje } \\
\text { Ubicua) } \\
\text { general por lo que no se limita a la formación recibida a } \\
\text { través del ordenador, o de nuestro dispositivo móvil (teléfo- } \\
\text { no, tableta), el concepto de ulearning incorpora cualquier } \\
\text { medio, (tecnológico en este caso) que permita recibir y } \\
\text { asimilar información e incorporarla al saber personal. Por } \\
\text { tanto, es preciso incluir dentro del mismo a la televisión } \\
\text { como elemento transmisor de información, mas ahora } \\
\text { cuando la televisión IP y la alta definición se convierten en } \\
\text { ventajas que permiten explotar las capacidades formativas } \\
\text { de este medio. } \\
\text { Implica la presencia de la tecnología en todos los momen- } \\
\text { tos y situaciones en los que una persona puede agregar un } \\
\text { nuevo conocimiento a su saber personal. La evolución de } \\
\text { la tecnología ha permitido ir rompiendo las ataduras que } \\
\text { la propia tecnología imponía a la formación, y vemos que } \\
\text { ya está presente en muchas de esas situaciones del aprendi- } \\
\text { zaje cotidiano. La posibilidad de aprender de una persona } \\
\text { cuando trabaja con su ordenador, cuando tiene a mano un } \\
\text { dispositivo móvil más o menos sofisticado, cuando se sienta } \\
\text { frente al televisor, cuando está compartiendo la web parti- } \\
\text { cipativa o cuando está viviendo su vida virtual, constituye } \\
\text { el objetivo del uLearning. }\end{array}$ \\
\hline
\end{tabular}



en la universidad desde una visión tridimensional.

\begin{tabular}{|c|c|}
\hline $\begin{array}{l}\text { MLEARNIG } \\
\text { (Aprendizaje } \\
\text { Movil) }\end{array}$ & $\begin{array}{l}\text { Concebido como un acceso a servicios formativos desde } \\
\text { dispositivos móviles, el mLearning ha supuesto un salto } \\
\text { importante en el avance hacia la ubicuidad de la formación. } \\
\text { Sin embargo, se ha visto también muy limitado, sobre todo } \\
\text { al principio, por las características de los terminales (pan- } \\
\text { talla pequeña, escasez de memoria, teclado restringido), } \\
\text { aunque ha ido ganando en importancia y en uso apoyado } \\
\text { precisamente en la superación de esas limitaciones: termi- } \\
\text { nales con mayor capacidad tecnológica, y aumento de la } \\
\text { velocidad de conexión, junto al abaratamiento de la misma. } \\
\text { Este crecimiento también se ha apoyado en la expansión del } \\
\text { uso de dispositivos tipo PDA como ordenador de bolsillo, } \\
\text { como agenda, como navegador GPS, como herramienta de } \\
\text { trabajo para profesionales que desempeñan su labor fuera } \\
\text { de una oficina: técnicos de mantenimiento, cobradores, } \\
\text { lectores de contadores, conductores, comerciales, } \\
\text { Es probable que un usuario no adquiera una PDA para } \\
\text { formarse, pero si ya la tiene, el paso natural es que la utilice } \\
\text { también en su formación. }\end{array}$ \\
\hline $\begin{array}{l}\text { BLEARNIG } \\
\text { (Aprendizaje } \\
\text { Mixto) }\end{array}$ & $\begin{array}{l}\text { Es el modo de aprender que combina la enseñanza presen- } \\
\text { cial con la tecnología no presencial. Como señala Brodsky } \\
\text { (2003). No es un concepto nuevo. Durante años hemos } \\
\text { estado combinando las clases magistrales con los ejercicios, } \\
\text { los estudios de caso, juegos de rol y las grabaciones de vídeo } \\
\text { y audio, por no citar el asesoramiento y la tutoría. }\end{array}$ \\
\hline ELEARNING & $\begin{array}{l}\text { Refiere las actividades formativas realizadas a través de, o } \\
\text { con ayuda de, la Red. Liberando a estudiantes y profesores } \\
\text { de la necesidad de coincidir en tiempo y lugar y cambian- } \\
\text { do esas ataduras por otras: la necesidad de disponer de un } \\
\text { ordenador, una conexión a la red y, además, que todo ello } \\
\text { funcionase bien. }\end{array}$ \\
\hline
\end{tabular}

Fuente: elaboración propia (2016)

Además, de lo presentado en el cuadro anterior, debe analizarse la llamada web2, que engloba a aquella parte de la web que está generada por los propios usuarios, quienes además de ser consumidores se convierten en creadores de la información al hacer uso de herramientas como los blogs, las wikis, las redes sociales, entre otros; pudiendo hacer llegar a millones de usuarios que los necesiten sus escritos, ideas y conocimiento sin mayor costo convirtiéndose en una útil vía de aprendizaje. El proceso de aprendizaje presenta cambios en donde existen tres niveles de conexión, entre comunidades especializadas, entre fuentes de información y redes, necesarios para generar nuevos conocimientos en esta sociedad mo- 
derna, basado en el desarrollo de habilidades y del uso de un entorno de aprendizaje creciente y personalizado. Ante todo lo expuesto, existe un cambio en la rutina pedagógica e incluso en la andragogía en los entornos educativos virtuales, necesario para lograr que el proceso educativo sea de forma significativa ante la modificación y actualización de diseños educativos adaptados a esta nueva era de la globalización e interacción mundial. La figura 2 recoge lo descrito anteriormente.

Figura 2. Rutina Pedagógica Virtual

\section{RUTINA PEDAGOGICA VIRTUAL}

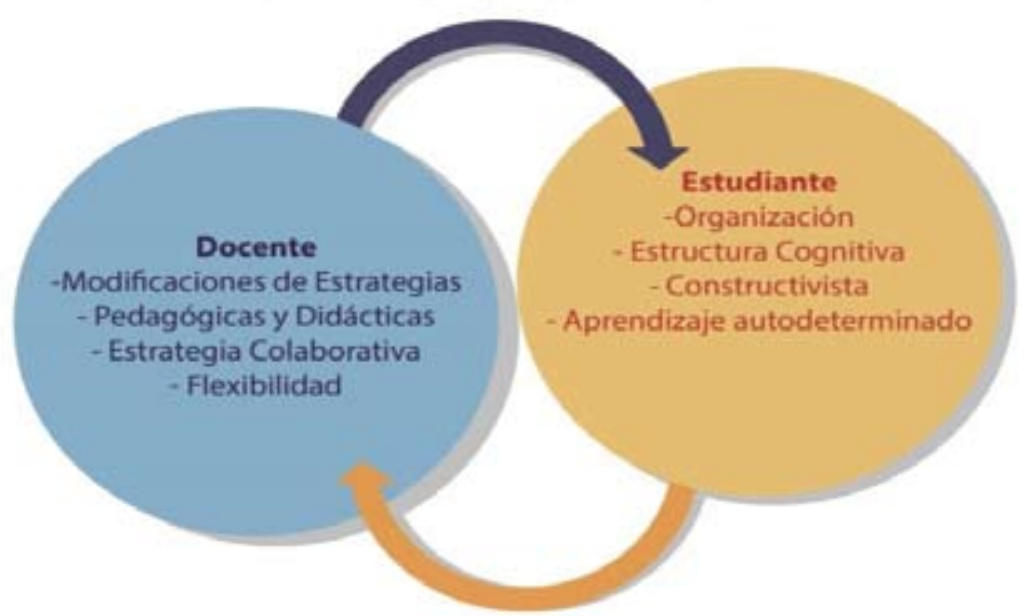

Fuente: elaboración propia (2016)

Como se puede observar en la figura 2, el docente debe realizar modificación de estrategias a nivel educativo y didáctica aplicada a las evaluaciones correspondientes, utilizando acciones colaborativas y flexibilidad en la interacción y socialización de saberes con los estudiantes. Por otra parte, el estudiante debe aplicar normas de organización acompañadas con una estructura cognitiva modificada por los cambios, donde construye conocimiento a través de los contenidos recibidos logrando la enseñanza con un aprendizaje autodeterminado. 


\section{Regulación normativa de la apropiación de las TIC en la universidad}

La compleja sociedad de la información y la comunicación unida a los profundos cambios y transformaciones que experimenta la economía mundial producto de la evolución tecnológica, han generado un dinámica, en donde la sociedad está avanzando mucho más rápido que sus instituciones y por tanto la capacidad generadora de normas para regular y potenciar en un entorno coherente esas realidades, quedando con frecuencia rezagada y superada por la dinámica cambiante. La universidad, por tanto debe propiciar y promover las ideas para la generación de una regulación normativa que auspicie el desarrollo de un nuevo modelo educativo, alternativo y flexible, que se potencia en el uso de las TIC, facilitando a los entes supervisores del estado los insumos teóricos y prácticos para delinear un marco legal general donde se armonicen las realidades novedosas que aporta la tecnología con las políticas de desarrollo local pero competitivas en el contexto de la globalización.

Al respecto, Rama, Mena \& Facundo (2008), señalan que la $\mathrm{EaD}$, se muestra como una voraz consumidora de modelos, lineamientos, criterios, estándares y demás propuestas que permitan determinar el grado en que un programa o carrera contará con apoyo y/o aprobación tanto social como oficial. En la investigación se plantea una teoría más acorde con el pensamiento jurídico contemporáneo, obligado a una búsqueda de la razón del derecho en la realidad de los hechos que deben ser normados al ritmo de su dinámica altamente cambiante. Por ello se toma la teoría tridimensional del derecho, que se sustenta en la integralidad y complementariedad necesaria de los tres elementos del derecho: el hecho, el valor y la norma.

\section{Método}

La integración de la información producto de la experiencia local en una Universidad privada de la región central de Venezuela, fue asumida desde el enfoque integrador transcomplejo, según el cual en el proceso de investigación se unifican momentos cualitativos con cuantitativos, a objeto de lograr la profundidad y am- 
plitud en el tratamiento de la realidad configurando una matriz epistémica multidimensional. Tal como lo expresa Schavino \& Villegas (2010), el enfoque integrador transcomplejo se sustenta en los principios epistemológicos de complementariedad, sinergética relacional, integralidad y reflexividad profunda. En correspondencia, con los principios metodológicos del trabajo en equipo y los multimétodos, que desde un diálogo transdisiciplianrio, cuyo eje es la reflexión-acción, lo que se manifiesta en un nuevo lenguaje que busque la integralidad del saber de la realidad investigada.

En correspondencia, en la dimensión metodológica se planteó la complementariedad metódica que tiene como objetivo explicar, comprender, transformar y re-crear la realidad estudiada. Actuando los investigadores desde distintas ópticas propias de sus disciplinas de adscripción, en la construcción de un diálogo continuo, que fluye en todas las direcciones. Específicamente en este caso, el diseño fue emergente y mixto, ya que se hace uso de métodos cuantitativos donde se incluyen lo explicativo, la inducción y deducción, así como los cualitativos: hermenéutica, estudio de casos, y la posterior contrastación y complementariedad mediante la abducción. En lo cuantitativo, se aplica una encuesta con base a un cuestionario a $6 \%$, equivalente a 905 de la población de estudiantes de pregrado de la Universidad caso de estudio. El mayor porcentaje $(85,30 \%)$, de la muestra tiene un rango de 20 a 30 años, lo que significa que el marco de trabajo se representa por una población mayormente joven. El 40,77\%, de la muestra no ha recibido ningún tipo de formación en el uso de las TIC; así mismo se visualiza el esfuerzo institucional de promover la formación ya que el 30,06 \%, ha recibido la misma a través de programas de formación institucional.

El cuestionario consta de 39 preguntas distribuidas en 4 partes, la primera orientada a caracterizar la muestra seleccionada; la segunda dirigida a la dimensión tecnológica; la tercera parte se orientó a la dimensión educativa y la última a la dimensión legal. Los datos obtenidos del cuestionario se estudiaron con base al análisis porcentual, posteriormente se cualificaron los datos mediante descripciones asociadas a la escala ad-hoc definida y que aprecia en el siguiente cuadro. 
La transcomplejidad de las tecnologías de información y comunicación en la universidad desde una visión tridimensional.

Cuadro 4. Escala Ad-Hoc

\begin{tabular}{|l|l|}
\hline Valor Cuantitativo (\%) & Juicio Cualitativo \\
\hline $0-30 \%$ & Muy Deficiente \\
\hline $31-60 \%$ & Deficiente \\
\hline $61-90 \%$ & Regular \\
\hline $91-100 \%$ & Bueno \\
\hline
\end{tabular}

Fuente: elaboración propia (2016)

La fase cualitativa, comprendió la aplicación de una entrevista con base a un guion de siete preguntas de final abierto, a los estudiantes, tomando un estudiante en representación de cada una de las escuelas activas, que ascienden a siete con la que se categorizó los aspectos relevantes de la usanza de las TIC en la institución caso de estudio, por parte de los actores participantes. La interpretación de los hallazgos se realiza a través de la categorización, posterior a lo cual se realizó la codificación y estructuración. En la fase integrativa se procedió a la triangulación individual por dimensión y la posterior triangulación global considerando los aportes de todas las dimensiones a fin de lograr una perspectiva integral de la realidad. Este proceso permitió delimitar las ocurrencias ocasionales en cuanto a las percepciones de los informantes claves sobre el tema así como las huellas de la existencia de una visión compartida de la realidad reflejada en la recurrencia de posiciones facilitando el desarrollo del principio de complementariedad.

\section{Resultados}

\section{Marco legal del uso de las TIC en la educación universitaria}

El estado del arte asociado al marco legal para el uso de las TIC en la educación universitaria latinoamericana, se logró al revisar la normativa existente y disponible en la web respecto al tema con base a lo cual se elabora el siguiente cuadro, donde es posible observar las semejanzas, diferencias y avances, entre aspectos. En general en Latinoamérica los gobiernos han sido lentos en el desarrollo de las acciones de regulación para el uso de las TIC en la educación universitaria. Ha predominado en ellos una actitud de desinterés, distracción y morosidad para incluir la modalidad en el conjunto 
de disposiciones y reglamentaciones nacionales. En los países donde se han conformado las normas en ningún caso han tenido el carácter de anticipatorias, sino que en general se han concentrado en el control de las iniciativas ya existentes.

Por su parte, la complejidad técnica, pedagógica y organizacional de la educación universitaria impone una dificultad en el establecimiento de las normas de regulación y la necesidad de actualización permanente de estas. De ahí que se hace necesaria la construcción de una normativa que regule los aspectos claves de la aplicación de las TIC en la educación universitaria a distancia en Venezuela, como un medio para obtener igualdad y equidad en la revolución educativa. No basta con una regulación especial, además se requiere una política y estrategia que incluya la evaluación de las instituciones y programas virtuales por parte de los pares académicos con pleno conocimiento de las lógicas intrínsecas de esta modalidad y sus implicaciones. Sin embargo, la tímida legislación que ha ordenado inicialmente la aplicación de las TIC en la educación universitaria en Venezuela y que podría sentar las bases para su desarrollo y reconocimiento como modalidad educativa sería tan importante como la presencial, se estancó a partir del año 2008.

\section{Marco legal para el uso de las TIC en la universidad caso de estudio}

Para interpretar la visión de los actores con respecto al marco legal para el uso de las TIC en la Universidad caso estudiado, se realizó una entrevista semiestructurada a tres directivos miembros del Consejo Universitario y se revisó la regulación interna existente. Se deduce que de la información aportada por los informantes emergen seis categorías, 18 subcategorías, 99 propiedades y 12 dimensiones. En relación a la primera categoría, leyes que hacen referencia al uso de las TIC se evidencian dos subcategorías: normativas internacionales, en este aspecto los informantes hacen mención de cinco normativas o documentos que hacen mención a las TIC. En la segunda categoría, legislación nacional emergen dos subcategorías normativas nacionales y acciones del Estado. En relación a la primera subcategoría normativas nacionales los informantes mencionan siete leyes o decretos. Así, la Constitución Nacional de la República Bolivariana de Venezuela (1999) en el Artículo 110 dice 
que el Estado reconoce la tecnología y sus aplicaciones como medio para desarrollo del país en todos sus aspectos y dispondrá de los recursos necesarios para su desarrollo y prevé la participación de los entes privados.

En tal sentido, el Decreto 825 (2000), de la Presidencia de la República establece el uso del internet como política prioritaria para el desarrollo de la nación. Por su parte el Decreto 3390 (2004), establece el uso del software libre como uso obligatorio para la administración pública nacional. Entre las más sofisticadas políticas tendientes a mejorar la conectividad y el uso de las TIC en el país se tiene el Plan de Alfabetización Digital (2006), la Misión Ciencias (2005), entre otras. En relación a la categoría Uso de las TIC en la educación universitaria, surgen dos subcategorías: realidad y requerimientos. En relación a la primera, se evidencia según los informantes que no existe una legislación que regule lo correspondiente a la Educación a distancia mediada por las TIC, por lo que este tipo de educación se muestra estancada. En algunos aspectos la relación puede ser punitiva. Se utilizan las TIC sin sustento, lo que puede ocasionar sanciones especialmente en las universidades privadas y el proceso de apropiación de las TIC es a largo plazo.

De ahí, emerge la subcategoría requerimientos, que implica desarrollar (consolidar) una cultura tecnológica, decisiones, amplitud de criterios, una educación centrada en principios, que integre la teoría y la práctica. Al respecto Villarroel (2011), señala que dado a que no existe normativa propia para la educación a distancia, la creación de instituciones o programas se sigue tratando como la modalidad presencial. Señala el autor que durante el año 2008 en el Núcleo de Vicerrectores Académicos se diseña una normativa que regularía la concepción, organización y desarrollo de la Educación a distancia con sus correspondientes especificaciones de mecanismos de aseguramiento de la calidad. Desde el año 2009, este proyecto fue sometido a la consideración del Consejo Nacional de Universidades sin que hasta la fecha, se haya aprobado. A su vez el uso efectivo de las TIC requiere competencias suficientes para que en su uso, desarrollen aplicaciones y contenidos específicos y las regulaciones en correspondencia. En la categoría Universidad igualmente emergen dos subcategorías: realidad señalando que el proceso de elaboración de la normativa de la Educación a distan- 
cia siendo para la informante 1 deficiente y para el informante 2 un proceso de evolución que pasó desde novedoso y elitesco, a uno donde no se dio promoción ni participación, fue rápido y donde se distorsionó el concepto de Educación a distancia hasta la actualidad donde lo califica con ajustes y variantes.

En la sexta categoría aspectos a regular de la normativa emergen siete subcategorías: conectividad que debe ser gratuita y de calidad, bibliotecas virtuales de calidad, la educación a distancia propiamente dicha que debe garantizar ser de calidad en general y en el diseño instruccional, las competencias del docente que deben ser de orden tecnológicas, pedagógicas y comunicacionales; así como sistemas de información institucional. La figura a continuación intenta representar la realidad de la dimensión legal de la apropiación de las TIC en la universidad caso de estudio.

Figura 3. Realidad de la dimensión legal de las TIC en la educación

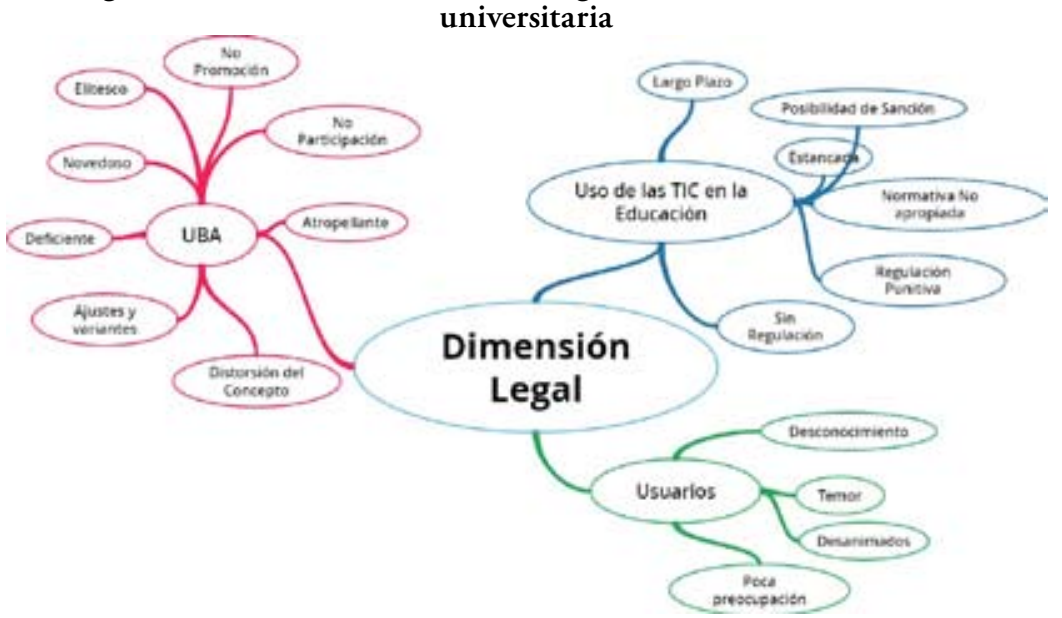

Fuente: elaboración propia (2016)

A efecto de dar una visión más amplia de la realidad de la dimensión legal en la universidad, se revisaron, además, los documentos: normativas, resoluciones, actas de reuniones que evidenciara que se ha hecho en esta materia, los hallazgos obtenidos permiten evidenciar en las categorías emergentes el avance de la dimensión legal de la EUAT en la universidad caso de estudio identificadas como: normativa legal, estructura, retroceso y logros. En cuanto a 
la normativa legal, se hacen evidentes las resoluciones emitidas por el Consejo Universitario, a los fines de adecuar la educación a distancia a las tecnologías de la información y la comunicación y a las expectativas de la Universidad.

La categoría estructura, que en sus subcategorías emergentes evidencia la evolución y modificación de ésta para adecuarse a las necesidades de la Universidad para favorecer su desarrollo. En este mismo orden de ideas y en consecuencia, surge la categoría retrocesos que tiene que ver con los cambios en la estructura que se han producido para tratar de mejorar la gestión y control. finalmente en la categoría logros emergen las subcategorías: modelo educativo institucional que considera como unos ejes de acción, la virtualización, la misión y objetivos del sistema de educación universitaria con apoyo tecnológico, todas las carreras digitalizadas y algunos de los programas de postgrado, programas de formación de docentes en el área y docentes capacitados.

\section{Apropiación de las TIC en la Universidad}

Para evidenciar el grado de apropiación de las TIC en la universidad, se procedió a la revisión de documentos relacionados a la conformación del parque tecnológico existente, así como la observación de éste, asociando el concepto de la UNESCO (2013), sobre la disposición de tecnologías en la educación y el acceso a estos. El análisis realizado dio cuenta de que la Institución dispone de equipos de escritorio, con un porcentaje de $36,16 \%$, distribuidos en los laboratorios que pueden ser utilizados por los estudiantes a los efectos de recibir clases prácticas; sin embargo no se cuenta con equipos en las aulas de clase para uso del docente en su estrategia formativa. Asimismo, se cuenta con servidores y conexión en el campus mas no se dispone de acceso libre a conexión inalámbrica, lo que limita la posibilidad de crecimiento con equipos que puedan tener a mano los estudiantes. En general, se cuenta con servicios de acceso a internet con dos operadoras. Sin embargo, en este particular influye el elemento presupuestario y administrativo. Se dispone de cuentas de facebook y twitter institucionales desde las cuales es posible comunicarse con los estudiantes y difundir información; esto, contrasta con el $15 \%$, que manifiesta tener cuentas 
de facebook personales y el 10\%, que tienen cuenta en twitter de acuerdo a los registros de datos de la universidad.

En cuanto a los procesos macro de evidencia que se cuenta con muchos de éstos informatizados, que luego se deprenden en docenas a razón de las opciones diseñadas para estudiantes, profesores y personal administrativo. Se cuenta además con un promedio de 840 programas formativos o asignaturas virtualizadas para uso de los estudiantes que se desempeñan en la modalidad en línea. En cuanto a la biblioteca digital, sucede que los estudiantes no ingresan para canalizar las búsquedas allí, toda vez, que los libros no están digitalizados e incluso el procedimiento de solicitud de préstamo se maneja de forma presencial. De acuerdo a lo anterior, la universidad debe implementar estrategias que fuercen al uso de la TIC, rediseńando los procesos y mejorando la dotación en servicios de internet y equipamiento de tecnología y equipos a fin de afianzar el modelo de educación mediada por TIC.

\section{Elementos intervinientes en la apropiación de las TIC en la universidad}

Los resultados se expresan en función de las cuatro dimensiones ya preestablecidas: estructural, tecnológica, educativa y legal. Los datos obtenidos del cuestionario se estudiaron con base al análisis porcentual.

Cuadro 20. Elementos Intervinientes en la apropiación de las TIC en la Educación Universitaria

\begin{tabular}{|l|r|}
\hline Dimensiones & \% Favorable \\
\hline Legales & 56,97 \\
\hline Estructurales & 45,44 \\
\hline Tecnológicos & 70,21 \\
\hline Educativos & 79,83 \\
\hline
\end{tabular}


Gráfico 5.

Elementos Intervinientes en la apropiación de las TIC en la Educación Universitaria

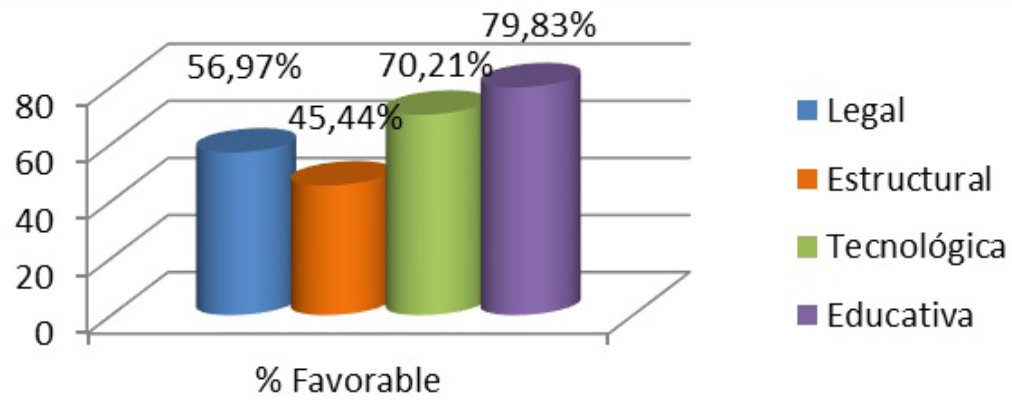

Fuente: elaboración propia (2016)

Los resultados del cuadro y gráfico evidencia que entre los elementos que más intervienen favorablemente en la apropiación de las TIC en la universidad son los de orden educativo en cuanto a su disposición y formación previa, seguidamente de los tecnológicos en cuanto al uso y desarrollo de la Infoestructura ubicándose en un $70,21 \%$, lo que se relaciona con una apreciación cualitativa regular. Por su parte, la mayor debilidad son los elementos estructurales en cuanto a la no posibilidad de acceso a internet en cualquier espacio de la universidad, especialmente en las aulas. Otra debilidad son los elementos de orden legal en cuanto a la inexistencia y poca difusión de las normativas existentes.

\section{Habilidades en el uso de las TIC en la universidad}

Para categorizar la usanza de las TIC en la institución de educación universitaria seleccionada, los informantes clave fueron siete estudiantes universitarios uno por carrera, escogidos de manera intencional de acuerdo a sus actuaciones académicas, conocimientos y experiencia en el área; a los cuales se realizó entrevistas individuales. De la información proporcionada, emergen seis categorías, 17 subcategorías, 43 propiedades y 37 dimensiones. En relación a la primera categoría, innovación, los informantes manifiestan que la educación mediada por las TIC facilita el desarrollo del proceso de aprendizaje con nuevas técnicas de estudios y una interacción entre el profesor y 
el estudiante sin importar las distancias. Se evidencian tres subcategorías: cambios de paradigmas, vías de integración de las TIC y motivación. Al respecto, Gómez (2007), señala que en los procesos de innovación en el uso de las TIC en las universidades el énfasis debe hacerse en la docencia, en los cambios de estrategias didácticas de los profesores centradas en desarrollar en los estudiantes habilidades de aprendizaje y en los sistemas de comunicación en lugar de enfatizar la disponibilidad y potencialidades de la tecnología.

La segunda categoría estudiantes, se refiere al sujeto que aprende en el proceso educativo. La educación mediada por TIC, permite desarrollar un proceso centrado en el estudiante respetando los diferentes estilos de aprendizaje y el reconocimiento a la diversidad. Se evidencian tres subcategorías. En relación a la categoría docentes, enfocada en el facilitador como parte activa del proceso educativo, se evidencian dos subcategorías: características, que abarca los elementos distintivos a través de los cuales se presentan como actualizados y abiertos y la subcategoría comunicación, referida a la interacción con los estudiantes donde se señala que no retroinforman a los estudiantes, lo que deja este marco comunicacional incompleto a los efectos del proceso de aprendizaje. La UNESCO (2004), refiere que la educación pueda explotar al máximo los beneficios de las TIC en el proceso de aprendizaje, es esencial que tanto los docentes como los estudiantes sepan utilizar estas herramientas, por lo que las instituciones deben liderar la capacitación en lo que respecta a nuevos métodos pedagógicos y nuevas herramientas de aprendizaje.

En la categoría requerimientos estructurales, que comprende las necesidades de disposición de tecnologías y elementos físicos indispensables para establecer la conexión telemática, emergieron cuatro subcategorías. Para la subcategoría conectividad, los informantes claves señalan dificultades en el acceso a internet por las limitaciones de ancho de banda nacional y por los costos asociados a los planes de navegación establecidos por las diferentes operadoras de servicio. Así, la infraestructura tecnológica de la universidad no responde a las necesidades del sistema de educación a distancia y no posee la potencialidad para responder a las expectativas del estudiante que busca opciones de flexibilidad educativa que sustituyan la necesidad de cumplir horarios rígidos. En la categoría aula virtual, debido a la diversidad de elementos intervinientes se 
evidencian tres subcategorías. La subcategoría favorable agrupa las consideraciones positivas de los informantes claves, entre las cuales se encuentran la percepción de facilidad de uso, acceso a la información y aprovechamiento de la oportunidad de disponer de múltiples actividades para lograr un aprendizaje independiente. Dese la visión de los informantes, la institución trabaja mucho en la preparación de las condiciones para garantizar el desempeño de los estudios mediados por TIC.

La tecnología que soporta la plataforma del aula virtual, es referida por los informantes como disponible, con una velocidad adecuada y sencilla de utilizar. En cuanto al aprendizaje, éste es completo, bajo un esquema interactivo, donde es posible la colaboración y el acceso para aclarar las dudas. La simbiosis del conocimiento en espacios virtuales se debe fundamentar en la interacción profesor-estudiante enfatizando la integración del conocimiento vinculado con una infraestructura tecnológica, así como el interés de apropiarse del resultado del proceso. En la subcategoría desfavorable, se muestran las debilidades que los informantes observan. En este sentido, expresan lentitud en la conexión, por lo que la consideran insuficiente, así como también indican las restricciones en el ancho de banda y la consecuente insuficiencia de los servicios ofrecidos a los usuarios del aula virtual. La consideración sobre el aprendizaje, se muestra influenciada al valorar si las materias son teóricas o prácticas, ya que para los estudiantes, las segundas son más susceptibles que las primeras de manejarse apropiadamente en el aula virtual.

De la misma forma, expresan que hay contenidos de baja calidad y hay evaluaciones intrascendentes que no significan un mayor reto para los estudiantes. Lo anterior atenta contra el proceso educativo en el aula virtual ya que éste debe fundamentarse en un alto nivel de significatividad para el estudiante, Asimismo, los informantes señalan que el servidor de la institución es deficiente y se observa lentitud en la conexión. En los aspectos asociados al profesor, los visualizan como dimensión no capacitados. En la categoría cultura computacional se recoge de los informantes que su desarrollo depende del uso adecuado de los recursos técnicos y de la disposición de los actores del proceso educativo de utilizar diversas herramientas existentes a través de internet como servicios de men- 
sajería, tal como el WhatsApp. De acuerdo a esto, la integración de la tecnología requiere un cambio en la política, reglamentaciones y responsables de la toma de decisiones a fin de asegurar la comunicación entre todas las partes. La cultura computacional implica acceso inmediato a la tecnología como mejor camino para obtener la información o las herramientas necesarias en la educación. De allí, que el aula virtual como medio y espacio de aprendizaje, apoyada en método y medios idóneos, facilita la conectividad del estudiante y la maximización del aprovechamiento del tiempo mediante el uso de dispositivos electrónicos.

Este escenario, promueve el acceso al conocimiento y ruptura de paradigmas, sin embargo, las limitaciones de infraestructura comprometen la efectividad de la educación mediada por tecnología, en la universidad como alternativa innovadora Lo anterior se visualiza en la figura 4, a continuación.

Figura 4.

Categorización unidad de análisis educación mediada por TIC

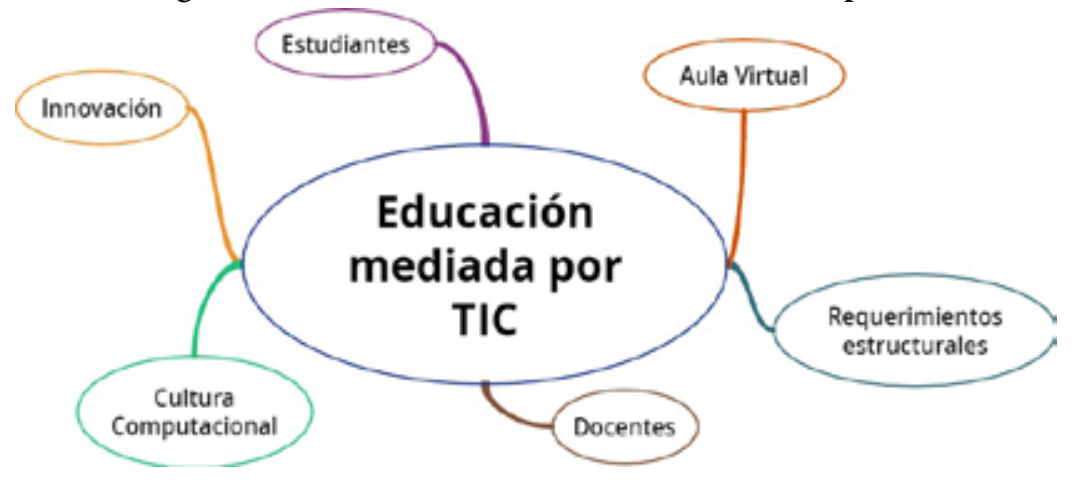

Fuente: elaboración propia (2016)

\section{Modelo educativo-currícular de la universidad}

Para caracterizar el modelo educativo-curricular de la universidad se revisaron, el modelo educativo 2015 y proyecto nacional de educación superior a distancia (2009). La información recabada referida al modelo educativo-curricular de la universidad evidencia que a este se le ha denominado enfoque curricular por competencias, transcomplejo de entropía autorregulada. lo que evidencia que 
se ha incorporado, al menos desde el punto de vista teórico, dos tendencias contemporáneas como lo son: el enfoque por competencias y la transcomplejidad. Con esto se busca el desarrollo de las capacidades complejas que permiten a los estudiantes universitarios pensar y actuar en diversos ámbitos. Por su parte, la transcomplejidad, es una tendencia en la cual un grupo de investigadores de la Universidad han sido sus principales proponentes y cuyo planteamiento básico es la complementariedad de visiones educativas. Es decir, no se descartan posturas, sino al contrario, se toman los aportes planteados por cada postura según los requerimientos de la situación educativa. En este sentido, se evidencia que la Universidad caso de estudio, no está ajena a la evolución de la educación a distancia, reconociendo que en la sociedad actual se requiere de realizar cambios basados en la incorporación de innovaciones educativas, en el uso racional de las tecnologías de la información y la comunicación. Todo ello dentro del marco de sistemas de formación avanzada, continua, abierta y crítica, que utilicen tanto la educación a distancia como otras modalidades educativas.

\section{Integración de resultados cuantitativos y hallazgos cualitativos}

A continuación, se presentan las categorías emergentes de cada dimensión, valoradas de acuerdo a los aspectos más resaltantes de la información documental, los resultados cuantitativos y los hallazgos cualitativos. En función de esto, es evidente, que tanto docentes como estudiantes desconocen las normativas y regulaciones en cuanto a educación universitaria a distancia mediada por las TIC y coinciden en reconocer que tal situación ha limitado su desarrollo y avances. Asimismo, tanto los resultados cuantitativos y los hallazgos cualitativos coinciden en establecer la necesidad de políticas y regulaciones que permitan su evolución y desarrollo, en tal sentido, es necesario actualizar la normativa nacional y realizar acciones para lograr su aprobación. Igualmente se plantea la necesidad de actualizar la conceptualización de la educación a distancia mediada por las TIC en función de los adelantos tecnológicos como se ha venido haciendo en Brasil. Al respecto lo planteado se resume en la figura 5, a continuación: 
Figura 5. Triangulación dimensión legal

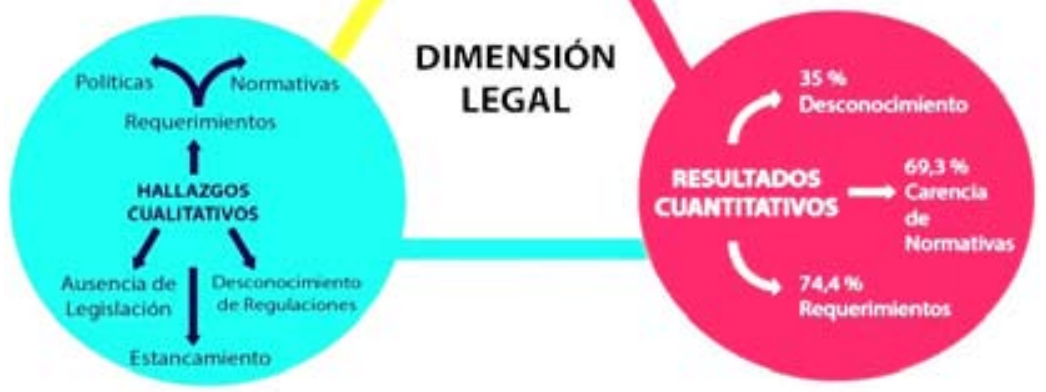

Fuente: elaboración propia (2016)

En relación la dimensión tecnológica se ratifica el sentido innovador del uso de las TIC en la educación, como cambio y transformación organizacional ampliando el espectro ya conocido en la educación en cuanto a modos y oportunidades. Por supuesto, esta oportunidad de acceso parte por garantizarse equipos y conexión a internet ante unos estudiantes que se caracterizan por desarrollar varias actividades en paralelo, como por ejemplo, estudian y trabajan, lo que requiere que aprendan a administrar eficientemente el tiempo. De igual forma, se revela la necesidad de una atención eficiente en cuanto a la matriculación e ingreso a las aulas virtuales, con respuestas oportunas propiciadoras de la interacción entre el estudiante y facilitador, a través de las cuales se disipe el miedo al cambio paradigmático. Indefectiblemente, propiciar innovación en cualquier espacio, coadyuva asumir las necesidades que afloran en el desarrollo y ejecución de la misma. La incorporación de las TIC en la educación universitaria requiere de condiciones de acceso a equipos, conexión, y servidores potentes que permitan canalizar 
la experiencia educativa universitaria. El bajo porcentaje favorable alcanzado en esta categoría (38,37\%), evidencia los altos requerimientos. La cultura computacional, como concepto conformado por el uso, aceptación y apropiación de los estudios mediados por TIC, no se evidencia en la universidad caso de estudio, lo cual se apoya en el bajo porcentaje de encuestados (28,95\%), que consideran adecuados los servicios y su adecuación a las necesidades de los estudiantes.

Figura 6. Triangulación dimensión tecnológica

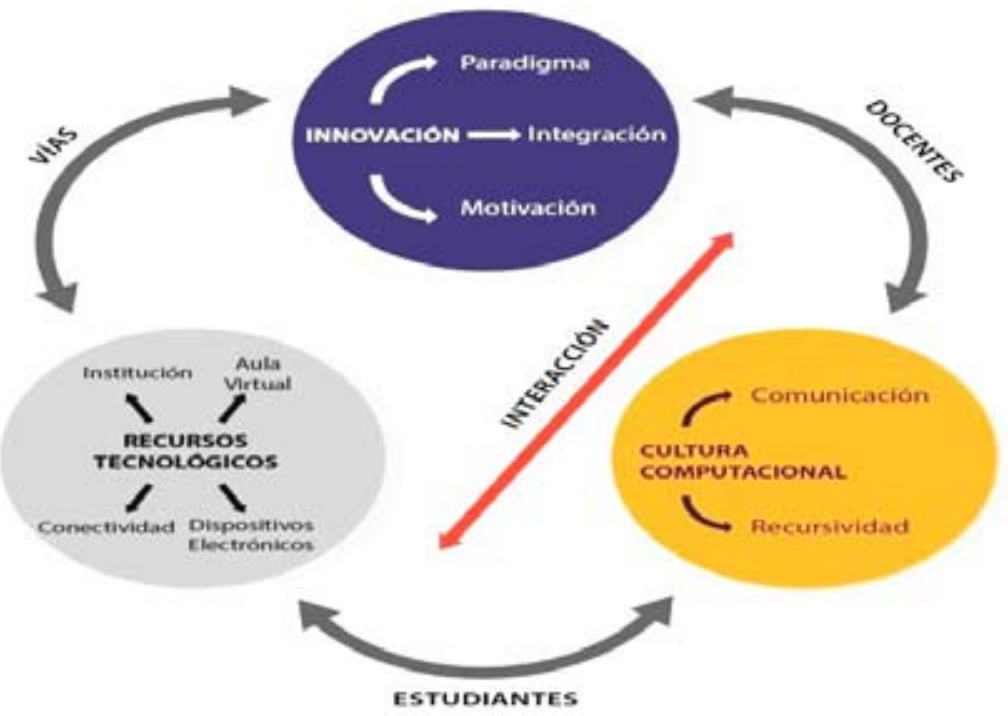

Fuente: elaboración propia (2016)

Los hallazgos de la dimensión tecnológica, presentados en la figura 6, muestran la relación entre los elementos destacados, como es los recursos tecnológicos, necesarios para lograr articular los dispositivos físicos, de conexión y aula virtual en una plataforma cónsona con la concepción de un espacio de aprendizaje abierto e interactivo. De igual forma, precisa el desarrollo de vías de integración de las TIC, afectado por los paradigmas y la poca motivación tanto de estudiantes y docentes, en los cuales debe propiciarse el desarrollo de una cultura computacional, que en la actualidad no se evidencia.A continuación, se presenta la triangulación de las 
categorías de la dimensión educativa donde intervienen el docente-facilitador y el estudiante-participante en el aula virtual, la cual requiere para su funcionamiento de una inversión constante, debido a que está sujeta a cambios, no obstante actualmente presenta lentitud. El estudiante hace un esfuerzo variable, requiere comunicación efectiva y señala que la evaluación subjetiva; así como un docente que requiere formación para adaptarse a un modelo educativo fundamentado en la complementariedad e intercolaboración.

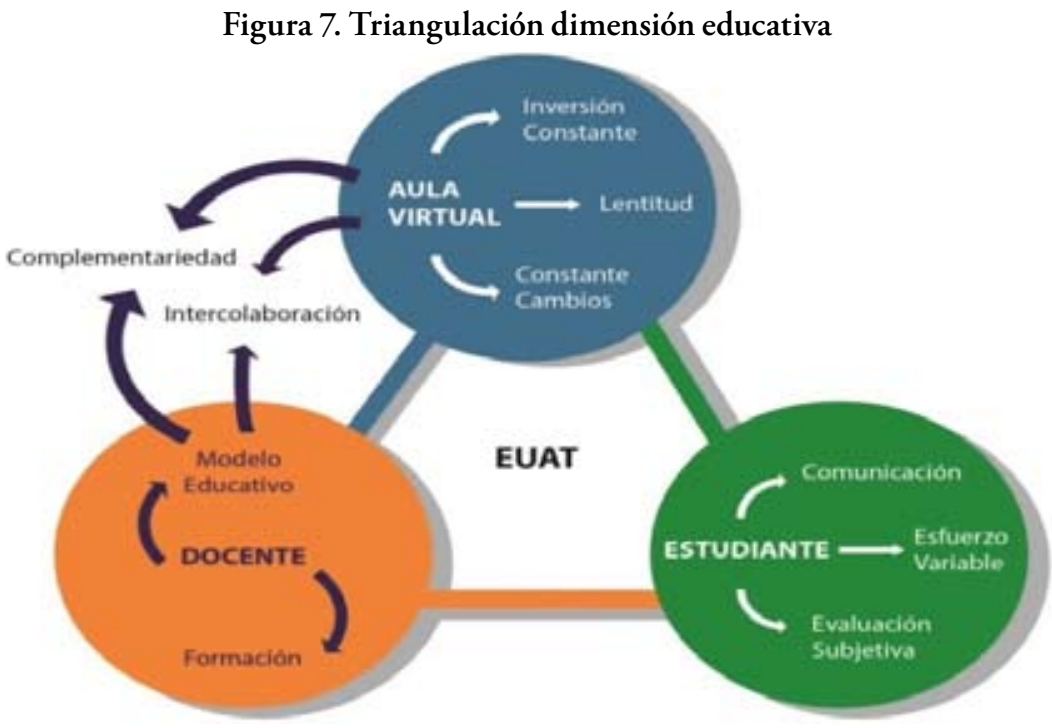

Fuente: elaboración propia (2016)

\section{Conclusiones}

El posmodernismo promueve ir más allá de lo esperado ante la complejidad y diversidad del mundo contemporáneo, lo cual evidencia la necesidad de asumir la complementariedad de aportes de disciplinas, teorías, perspectivas, métodos y criterios para dar respuestas a las diferentes interrogantes de múltiples realidades presentes en la apropiación de las TIC en la universidad. Todos los días lo legisladores se encuentran frente a la posibilidad que sus decisiones conduzcan a imprevisibles fluctuaciones con consecuencias desconocidas. Es por ello que es necesario modificar los hábitos ad- 
quiridos por los juristas de pensar sobre la base de un paradigma determinista, mecanicista, que opera linealmente con los conceptos de causa o efecto (o de imputación y sanción como diría la teoría pura del derecho). El contexto universitario exige modelos actualizados inherentes a una nueva forma de aprender a través de las TIC, con transformaciones pedagógicas, andragógicas y didácticas adaptadas las nuevas generaciones, que requieren pensamientos complejos que les permitan enfrentar el mundo diverso que enfrentan día a día.

A tales efectos, se cuenta con diferentes paradigmas, nuevos conceptos y estructuras educativas enlazadas en red, que le permita lograr aprendizaje significativo a los estudiantes. Es decir, exige una conjunción de saberes, capaces de producir conocimientos integrados, plurales, con diferentes puntos de vista, utilizando diferentes enfoques, teorías, perspectiva y métodos, producto de las inquietudes y experiencias de múltiples sujetos, entre estos de los actores educativos. Se deduce entonces, la necesidad de transformación del docente tradicional a un facilitador virtual complejo que cumple múltiples roles y asume una nueva cultura basada en diversas estrategias de aprendizaje haciendo énfasis en el acercamiento a múltiples teorías y tendencias educativas en la interpretación de saberes de manera complementaria y transdisciplinarias de lugar a la transcomplejidad.

La apropiación de las TIC como un proceso transcomplejo, implica la interacción entre el ser humano con lo tecnológico. Intervienen en este caso, los paradigmas referidos al ser humano, sus convicciones, sus creencias y miedos ante el uso de la tecnología como elemento de ciencia en sus actividades de aprendizaje. En consecuencia, la apropiación implica reorganización de pensamiento y su configuración en la realidad, relacionando la filosofía de la tecnología, con la psicología como ciencia que estudia la conducta y los procesos mentales de los individuos y a través de los cuales se puede modificar las creencias. Una disciplina fundamental en la visión transcompleja de la tecnología es la economía por los aspectos de orden financieros que implica su apropiación en la universidad.

En concordancia con lo anterior, desde la transcomplejidad de la dimensión tecnológica es posible plantear en la educación mediada por TIC una nueva visión del trabajo didáctico dentro y fuera 
del aula universitaria, que permita tejer, trenzar, articular y unir el principio con el final, incorporar el azar, incertidumbre, y autoorganización en el proceso de aprendizaje, en un medio mucho más complejo y amplio como es el espacio virtual.

\section{Referencias bibliográficas}

Asamblea Nacional, (2009). Ley Orgánica de Educación. Gaceta Oficial de la República Bolivariana de Venezuela

Carneiro, R., Toscano, J. C., \& Díaz, T. (2009). Los desafíos de las TIC para el cambio educativo. Fundación Santillana: Madrid.

Carrillo (2010) Modelo Teórico desde la estrategia de gobierno electrónico para la transformación de la gestión universitaria en la región centro-occidental. Tesis no publicada.

Cámara Venezolana de Comercio Electrónico. (2006). Estadísticas de Internet en Venezuela. Disponible en: http://cavecom-e.org.ve/index.php?option=com_zoo\&view=category\&Itemid $=112$

CEPAL, (2000). Ranking de la conectividad al internet en Latinoamérica. Disponible en: http://www.cepal.org/es/comunicados/cepal-aumenta-fuertemente-uso-acceso-internet-america-latina-caribe

Constitución Bolivariana de la República de Venezuela (1999). Gaceta Oficial de la República Bolivariana de Venezuela 36.860. Extraordinario. Diciembre 30 de 1999.

CRUE (2013). University 2013: Situación actual de las TIC en el sistema universitario español. Edición: 2013. ISBN: 978-84-938807-6-7

Ley de Educación Superior (2002) Aprobado en la primera discusión por La Asamblea Nacional el 21 de Agosto de 2001. Asamblea Nacional 09 de Noviembre de 2001.

Ministerio de Ciencia y Tecnología (2005). Ley Orgánica de Ciencia, Tecnología e Innovación. República Bolivariana de Venezuela.

OPSU (2008.) Normativa para la educación superior a distancia. En proceso de validación. Inédito.

Orozco, P. (2014) Incidencia del aprendizaje del inglés en la universidad de San Buenaventura - Seccional Cartagena. Artículo publicado en la revista Avances de la investigación formativa y aplicada 2012-2013 de la Universidad de San Buenaventura, Cartagena.

Programa de las Naciones Unidas para el Desarrollo (2001). Informe sobre Desarrollo Humano 2001. Poner el adelanto tecnológico al 
servicio del desarrollo humano. Disponible en: http://hdr.undp.org/ en/media/hdr_2001_es.pdf

Rama, Mena \& Facundo. (2008), La diversidad de la construcción de los marcos normativos de la Educación a distancia $(\mathrm{EaD})$ en América Latina. Ediciones Hispanoamericanas Ltda., Bogotá, Colombia.

República Bolivariana de Venezuela (1999). Constitución de República Bolivariana de Venezuela

Sáez (2011). Utilización eficaz y actitudes que muestran los docentes en la aplicación de las tecnologías de la información y comunicación en educación primaria.

Schavino \& Villegas (2010). De la teoría a la praxis en el enfoque integrador transcomplejo. Disponible en: http://www.adeepra.org. ar/congresos/Congreso\%20IBEROAMERICANO/EIC/R0721_ Schavino.pdf

Tedesco, J. C. (2005). Las TIC y la desigualdad educativa en América Latina, presentado en el Tercer Seminario "Las tecnologías de información y comunicación y los desafíos del aprendizaje en la sociedad del conocimiento", realizado entre el 30 de marzo y el 1 de abril de 2005, en Santiago de Chile, Seminario CEDI/OCDE de habla hispana.

Unesco (2004). Las tecnologías de la información y la comunicación en la formación docente Guía de planificación. División de Educación Superior

Unesco (2005). Hacia las sociedades del conocimiento. Disponible en: http://unesdoc.unesco.org/images/0014/001419/141908s.pdf

Valdez, A (2014). Inteligencia de negocios aplicada a través de un sistema de información gerencial como estrategia para los procesos académicos y administrativos. Trabajo de grado para optar al título de Magister en Gerencia de Tecnología de la Información. Valencia: UJAP Villarroel, C (2011). El aseguramiento de la calidad en la Educación Superior Venezolana. El aseguramiento de la calidad de la Educación Virtual. Perú. Grafical Real. 